\title{
Treatment of Pica Behavior with Olanzapine
}

\section{To the Editor:}

August 24, 2007

Pica behavior, the ingestion of items not generally recognized as food, is a diverse syndrome with multiple possible etiologies. Explanations of its pathogenesis include seeking trace mineral supplementation, psychosis, and purposeful self-injury. ${ }^{1}$ Associated conditions include iron-deficiency anemia, pregnancy, malnutrition, and chronic renal insufficiency. Pica behavior shares features similar to bulimia, trichophagia, and obsessive-compulsive disorder. ${ }^{2,3}$ The neural basis is unknown, although brains levels of neuropeptide $Y$ and opiates may mediate appetite, and intra-ventricular administration of neuropeptide $Y$ induces pica in rats. ${ }^{4}$ Treatment of has focused mainly on behavioral approaches to single aspects, such as cigarette pica. ${ }^{1}$ Selective serotonin reuptake inhibitors (SSRIs) may help some individuals. ${ }^{2}$ In this report, a case of an autistic adult with severe pica behavior responded dramatically to olanzapine.

\section{CASE DESCRIPTION}

A 42-year-old woman with severe mental retardation, autism, and seizure disorder was residing in a group home. She had a long history of pica behavior, involving cigarette butts, socks, pieces of cloth, and many small objects. On examination, she was nonverbal and had severe stereotypies including rocking and repetitive grunting. Cranial nerve, motor, and gait exams were unremarkable. She began treatment with the SSRI fluvoxamine with no effect on this behavior. She was then started on olanzapine 2.5 $\mathrm{mg} /$ day, with a marked reduction in pica behavior noted by caregivers. This response has been maintained for over 36 months. The remainder of her behavioral syndrome was unchanged by these medications.

\section{DISCUSSION}

The concept of pica as a survival instinct related to trace mineral nutritional deficiency is only applicable in populations where this is an issue. Otherwise, additional conceptualizations are required.
This patient had prominent frontal disinhibitory behavior syndrome which occurs in a variety of disorders affecting the frontal lobe, anterior cingulate gyrus, or thalamus. These disorders include infarction, herpes encephalitis, frontal neoplasms, frontotemporal dementia and attention-deficit/hyperactivity disorder ${ }^{5,6}$ "Utilization behavior" ${ }^{5}$ is thought to occur as a consequence of parietal lobe release, causing the subject to become excessively dependent on visual and tactile stimulation from the outside world. The patient's pica behavior was markedly reduced by olanzapine, an antipsychotic with prominent effects on dopaminergic, serotoninergic, adrenergic, and cholinergic systems.' The use of neuroleptics to treat pica behavior has not been reported.

While treatment success in this case may be a pseudo-specific effect of olanzapine, the efficacy of antipsychotics versus other medication classes and behavioral treatments in altering this chronic and often refractory behavior warrants further study.

Sincerely,

Alan Jay Lerner, MD

\section{REFERENCES}

1. McAdam DB, Sherman JA, Sheldon JB, et al. Behavioral interventions to reduce the pica of persons with developmental disabilities. Behav Modif. 2004:28:45-72.

2. Frey AS, McKee M, King RA, Martin A Hair apparent: Rapunzel syndrome. Am J Psychiatry. 2005;162:242-248.

3. Gundogar D. Demir SB, Eren I. Is pica in the spectrum of obsessive-compulsive disorder? Gen Hosp Psychiatry. 2003;25:293-294.

4. Madden LJ, Seeley RJ, Woods SC. Intraventricular neuropeptide $Y$ decreases needinduced sodium appetite and increases pica in rats. Behav Neurosci. 1999;113:826-832.

5. Lhermitte F. 'Utilization behaviour' and its relation to lesions of the frontal lobes. Brain. 1983; 106:237-255.

6. Archibald SJ, Mateer CA, Kerns KA. Utilization behavior: clinical manifestations and neurological mechanisms. Neuropsychol Rev. 2001:11:117-130.

7. Tollefson GD, Sanger TM. Negative symptoms: a path analytic approach to a double-blind, placebo- and haloperidol-controlled clinical trial with olanzapine. Am $J$ Psychiatry. 1997; 154:466-474.

Dr. Lerner is associate professor of neurology at Case Western Reserve University in Cleveland, Ohio, and director of the Memory and Cognition Center at the Neurological Institute of University Hospitals Case Medical Center.

Acknowledgment: The author thanks Robert Daroff, MD, for his critical review and helpful suggestions regarding this manuscript.

Disclosure: Dr. Lerner does not have an affiliation with or financial interest in any organization that might pose a conflict of interest. 